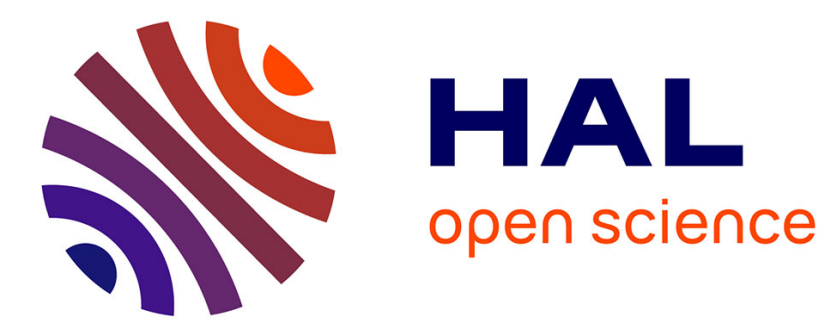

\title{
Cartography: John Snow and the Topography of Cholera Sebastian Grevsmühl
}

\section{To cite this version:}

Sebastian Grevsmühl. Cartography: John Snow and the Topography of Cholera. Béatrice Delaurenti; Thomas Le Roux. Cultures of Contagion, MIT Press, pp.55-63, 2021. hal-03451698

\section{HAL Id: hal-03451698 https://hal.science/hal-03451698}

Submitted on 26 Nov 2021

HAL is a multi-disciplinary open access archive for the deposit and dissemination of scientific research documents, whether they are published or not. The documents may come from teaching and research institutions in France or abroad, or from public or private research centers.
L'archive ouverte pluridisciplinaire HAL, est destinée au dépôt et à la diffusion de documents scientifiques de niveau recherche, publiés ou non, émanant des établissements d'enseignement et de recherche français ou étrangers, des laboratoires publics ou privés. 


\section{CARTOGRAPHY \\ John Snow and the Topography of Cholera}

Sebastian V. Grevsmühl

The analysis of contagion through maps has a long tradition. The Englishman John Snow (1813-1858) is a particularly renowned figure in this field. $\mathrm{He}$ is considered a pioneer of statistical mapping and one of the founding fathers of modern epidemiology. Although he published only two "epidemiological" maps during his career, he appears in all the major textbooks on the history of medicine, cartography, and, more recently, infographics. $\mathrm{He}$ is systematically cited for having contained a severe cholera epidemic in the mid-nineteenth century in the Soho district of London by using a powerful method of statistical visualization: the dot map. Dean of visual methods Edward Tufte writes that Snow's maps enabled him "to discover the cause of the epidemic and bring it to an end." This compelling story is appealing in that it is short, dramatic, and heroic. ${ }^{2}$ Many variations of Snow's maps have since been produced, some of which have become truly iconic, and continue to inspire practitioners of visualization methods from a variety of disciplines.

The problem, however, is that a number of historical studies have shown that Snow never actually claimed to have discovered the cause of the epidemic thanks to a map. In fact, he himself preferred to much more cautiously describe his map as a "diagram of the topography of the outbreak." Moreover, despite their simplicity, Snow's two maps failed to convince the majority of his peers, who continued to advocate miasmatic theories, that is, contagion by airborne vapors. This has unfortunately escaped the majority of his commentators, who have not bothered to reconstruct his rigorous 
scientific approach. A number have attributed great power to Snow's maps, considering them to be the analytical tools of his thought, which is in fact quite debatable. Ultimately, such accounts say more about the intentions of their authors than the historical role of these famous maps.

What, then, was the function of Snow's maps, and what was his thought process? The best-known dot map in his work (figure 1) depicts the Soho district of London, modified by Snow to pinpoint cholera deaths that occurred over a six-week period between August and September 1854 by means of small black bars. He also used circles to indicate the location of thirteen public water pumps. But rather than being the source of a spectacular discovery, as has often been alleged, this map is a specific case study forming part of much broader fieldwork and intellectual research carried out by Snow over the course of many years at various sites.

Snow saw cholera firsthand on several occasions. In 1831, during the first of four major pandemics that ravaged England over the course of the nineteenth century, he was a medical assistant. At the time of the second epidemic, which occurred between 1848 and 1849, he worked as a doctor in London. It was then that he first theorized the transmission of cholera based on his clinical observations. He published this theory in 1849 , without a supporting map, arguing that the key vector of cholera transmission was the contamination of drinking water by sewage. His theory openly opposed the dominant miasmatic theories, yet his argument raised a fundamental problem: as he himself remarked, "we are never informed in works on cholera what water the people drink."

When a new epidemic struck England in 1853 and 1854, Snow decided to take advantage of the situation to fill in the data gap on water and to support his theory. To this end, he conducted two separate studies. One examined the links between cholera deaths and the practices of two water companies supplying water to the south end of London. The other, in a much more circumscribed way, concerns the Soho area. Published in 1855 as an expanded version of his On the Modes of Communication of Cholera, the results of these two projects also include the famous map of the Broad Street neighborhood (figure 1). The latter was meant to synthesize and illustrate his investigative work and to spatialize some of the

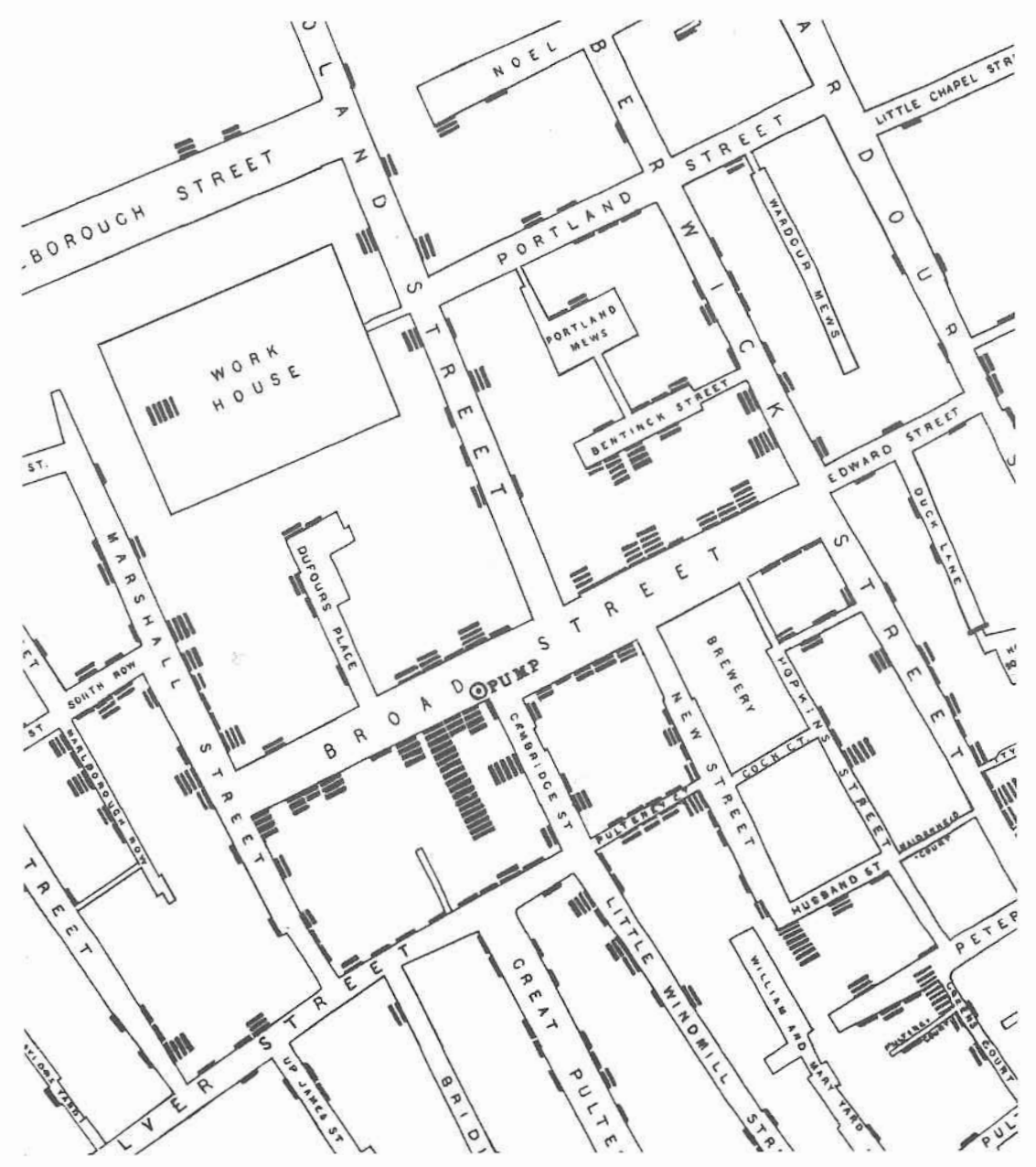

Figure 1

Detail of Snow's dot map showing cholera deaths in August and September 1854 in London around Broad Street (black bars) and water points (circles). Source: John Snow, On the Mode of Communication of Cholera, 2nd ed. (London: Churchill, 1855), 44-45. 
epidemic's effects. In particular, it can be seen that the mortality rate is higher near the Broad Street water pump. But the cartographic reasoning stops there: the conclusion that the water from the Broad Street pump is the probable vector of the contagion, which prompted the authorities to remove the arm of this pump in September 1854, is based on the analysis of other elements.

The strength of the visual, but also its weakness, lies in the fact that each visualization process creates its own economy of visibilities and invisibilities. Everything that can be seen and everything absent from a map informs and potentially alters the narrative. In Snow's case, the invisibilities produced by the simple choice of map type weighs heavily on the development of the account. For example, one of the strong assumptions of the dot map is that it implies a more or less uniform distribution of people across the mapped space. If some houses do not have black bars, it is presumed that the inhabitants of these houses have successfully avoided contagion, whereas this may simply be due to the small number or even absence of people. In other words, mapping methods are never neutral, and biases also appear in alternative mapping techniques, such as the continuous tonal gradation method introduced by Quetelet to visualize variations in mortality as a function of population density.

In addition, Snow's map contains many anomalies, both visible and invisible, which require explanations only obtainable through a field survey. For example, the fact that some inhabitants are located close to the probable source of contagion does not necessarily lead to high mortality rates. Curiously, those who frequented the poor house on Poland Street and the workers of the Broad Street brewery remained largely untouched. It is only during his investigation that Snow learns these institutions have their own water sources-something the map does not show. In a similar vein, several deaths that occurred at a considerable distance from the source can be explained by regular use of the Broad Street pump.

A second map constructed by Snow also exists, published just six months later (figure 2), which is considerably less well known and rarely cited. However, it reflects Snow's desire to more precisely define a "cholera zone," particularly from a visual perspective. To this end, he added a dotted

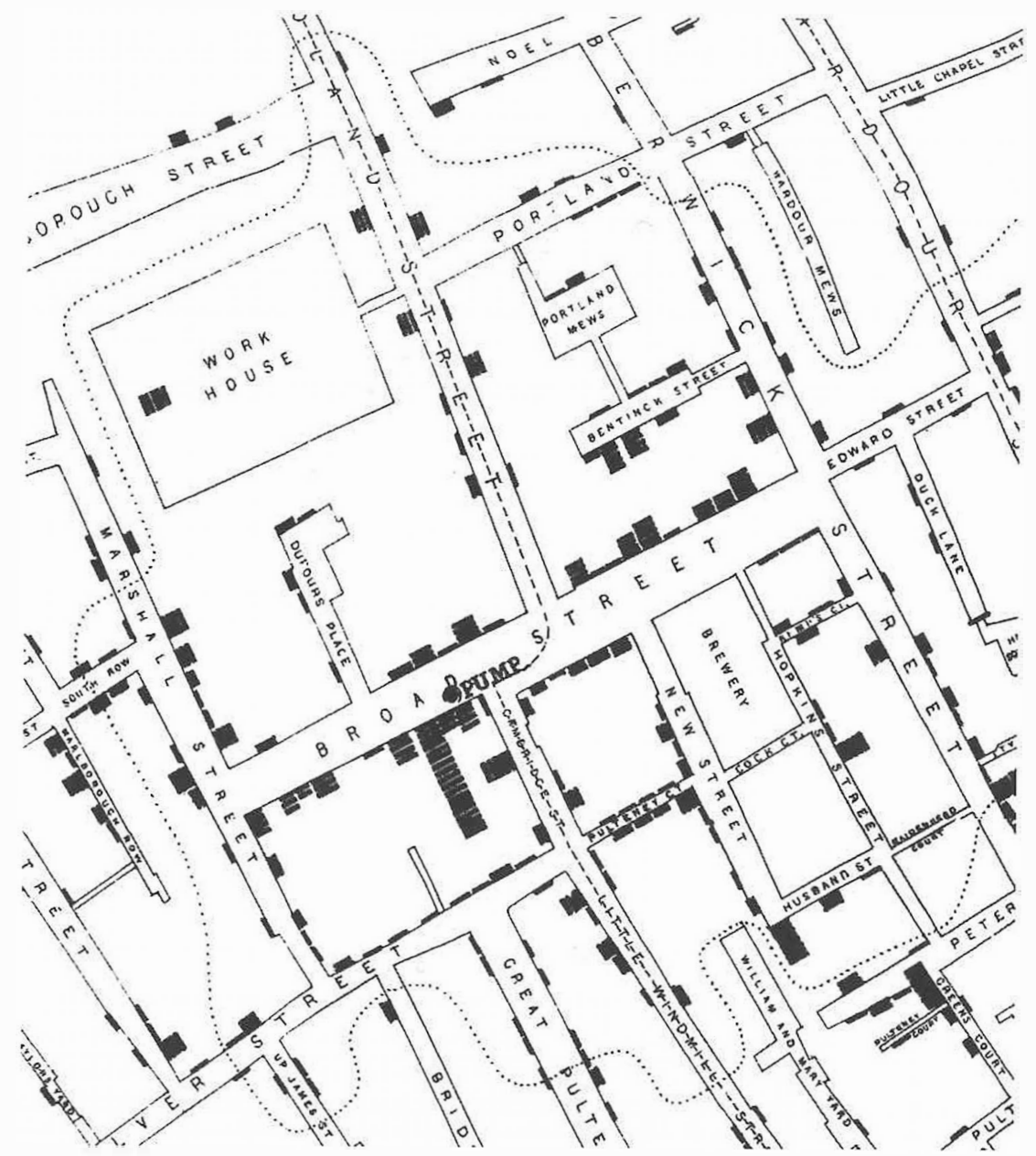

\section{Figure 2}

Detail from Snow's second dot-density map showing the addition of an equidistance line. Source: Cholera Inquiry Committee, Report on the Cholera Outbreak in the Parish of St. James, Westminster during the Autumn of 1854 (London: Churchill, 1855), 106-107. 
line to his original map that establishes the median pedestrian distance between the Broad Street pump and other nearby pumps. The highly irregular line was added to counter miasmatic theories that suggested a much more regular spatial contagion. Despite this effective visual novelty, Snow's opponents remained dubious, demonstrating that a map's interpretation can vary considerably depending on the authors and their intentions.

Indeed, Snow was not the only one to have published dot maps of this critical cholera episode. Others who came before (Edmund Cooper) and after (members of a scientific commission) produced maps that were often much more detailed, showing house numbers, a more comprehensive differentiation of deaths, and the sewer system superimposed on the neighborhood map. But the conclusions drawn from these maps all challenged Snow's theory. For example, members of the Committee for Scientific Inquiries of the General Board of Health strongly rejected his water transmission theory using the very same type of map, identifying instead an atmospheric influence of unknown origin, likely related to emanations from new sewers.

This much is clear: what is frequently presented as visual evidence is not actually so once we consider the context in which the cartographic object was made. Today, as infographics become omnipresent, there is a great temptation to transform historical cartographic objects into precursors of visual tools for "good" governance. In most cases, however, we depart considerably from historical realities to make this or that argument. In this way, when historians of cartography give a central place to Snow's map, they do so to support their own narrative of the centrality of visual thought in the sciences.

Today, mapping and contagion form an inseparable couple that often produces very useful public health results, especially when the mechanisms of contagion are known. The historical analysis of Snow's maps reminds us, however, that in the absence of a common paradigm of contagion, the visualization of spatial data relationships becomes a very complex analytical terrain, far from the simplistic explanations provided by heroic narratives. The latter, in fact, dangerously overestimate the power of the visual at the expense of more elaborate historical explanations. No one wins in this process, not historians, not visual culture specialists, nor political decision-makers.

translated by Maya Judd

\section{NOTES}

1. Edward Tufte, Visual Explanations (Cheshire: Graphics Press, 1997), 27.

2. Kari McLeod, "Our Sense of Snow: The Mych of John Snow in Medical Geography," Social Science and Medicine 50 (2000), 923-935.

3. John Snow, On the Mode of Communication of Cholera (London: Churchill, 1855), 45.

4. Cired by Tom Koch, "The Map as Intent: Variations on the Theme of John Snow," Cartographica 39, no. 4 (2004), 3.

\section{SELECTED BIBLIOGRAPHY}

Brody, Howard, Michael Russell Rip, Peter Vinten-Johansen, Nigel Paneth, and Stephen Rachman. "Map-Making and Myth-Making in Broad Street: The London Cholera Epidemic, 1854." Lancet 356 (2000): 64-68.

Cholera Inquiry Committee. Report on the Cholera Outbreak in the Parish of St. James, Westminster during the Autumn of 1854. London: Churchill, 1855.

Koch, Tom. "The Map as Intent: Variations on the Theme of John Snow." Cartographica 39, no. 4 (2004): $1-14$.

MacLeod, Kari. "Our Sense of Snow: The Myth of John Snow in Medical Geography." Social Science and Medicine 50 (2000): 923-935.

Tufte, Edward. Visual Explanations. Cheshire: Graphics Press, 1997.

Vinten-Johansen, Peter, Howard Brody, Nigel Paneth, Stephen Rachman, and Michael Rip, with David Zuk. Cholera, Chloroform, and the Science of Medicine: A Life of John Snow. Oxford: Oxford University Press, 2003. 